\title{
CONTRASTES NA AGRICULTURA FLUMINENSE: O TRADICIONAL E O MODERNO NO PROCESSO DE COMERCIALIZAÇÃO AGRÍCOLA ${ }^{1}$
}

\section{CONTRASTS IN RIO DE JANEIRO AGRICULTURE: TRADITIONAL AND MODERN ELEMENTS IN THE AGRICULTURAL COMMERCIALIZATION PROCESS}

\author{
Glaucio José Marafon ${ }^{2}$, Rogério Seabra ${ }^{3}$ \\ ${ }^{2}$ Universidade do Estado do Rio de Janeiro (UERJ), Rio de Janeiro, RJ, Brasil \\ ${ }^{3}$ Instituto Brasileiro de Geografia e Estatística (IBGE), Rio de Janeiro, RJ, Brasil
}

Correspondência para: Glaucio José Marafon (glauciomarafon@hotmail.com)

doi: $10.12957 /$ geouerj.2016.23485

Recebido em: 19 fev. 2016 | Aceito em: 2 mai. 2016

\section{SCREENED BY $\checkmark$ iThenticate}

\section{RESUMO}

A análise das atuais transformações no campo torna-se fundamental pois, além de desempenhar as funções tradicionais de fornecer mão de obra e matérias-primas para a cidade e consumir produtos dela oriundos,o campo abriga, cada vez mais, atividades não agrícolas como a produção industrial e os serviços associados às atividades de turismo, que valorizam as áreas com aspectos naturais. Esse processo ocorre intensamente no estado do Rio de Janeiro, afinal este apresenta uma configuração territorial marcada pelo intenso processo de urbanização.Destarte, o objetivo central desse trabalho é o de compreender como o tradicional e o moderno atuam concomitantemente no processo de comercialização agrícola, e como o setor mais moderno de produção agrícola absorve a produção e os excedentes dos produtores tradicionais, compreendendo assim permanências e transformações na agricultura fluminense como elementos convergentes.

Palavras-chave: espaço rural fluminense; permanências e mudanças no campo, rede de comercialização agrícola.

\begin{abstract}
The analysis of current changes in the countryside becomes crucial. Besides both performing traditional functions as provider of urban workforce and raw materials and consuming goods from the city, the countryside becomes more and more a place for non agricultural activities such as industrial manufacturing and services related to tourism that make it natural features stand out. The state of Rio de Janeiro, the territory of which is marked by an intense urbanization process, exemplifies these changes intensely. This work aimed to understand how the permanence of traditional elements and the presence of modern ones affect the process of commercializing the agricultural output and how the most modern sectors of agricultural production absorbs the output and surpluses from traditional farmers. Results allow understanding continuities and changes in Rio de Janeiro agriculture as converging elements.
\end{abstract}

Keywords: Rio de Janeiro rural area; continuities and changes in the countryside; agricultural commercial network.

\footnotetext{
1 Esse artigo é um dos resultados de pesquisas desenvolvidas no Núcleo de Estudos de Geografia Fluminense NEGEF/UERJ.
}

(C) 2016 Marafon e Seabra. Este é um artigo de acesso aberto distribuído sob os termos da Licença Creative Commons Atribuição-Não Comercial-Compartilha Igual (CC BY-NC-SA 4.0), que permite uso, distribuição e reprodução para fins não comercias, com a citação 


\section{INTRODUÇÃO}

O tradicional e o moderno não representam um contraste na agricultura; ao contrário, a permanência de formas pretéritas é condição para o surgimento, crescimento e manutenção do moderno. No caso da agricultura fluminense, há formas distintas de observar o tradicional e também o moderno.

Podemos iniciar observando o tradicional nas relações de poder arcaicas, relacionadas ao latifúndio, presentes na Região Norte Fluminense. O passado continua (e por vezes é potencializado) mesmo com o crescimento de atividades novas, como a extração de petróleo. 0 tradicional também é observado nas relações de trabalho informais e precárias, envolvendo pequenos produtores rurais na Região Serrana do estado.

O moderno está presente nos mecanismos de comercialização que envolvem os mesmos produtores rurais dominados por relações trabalhistas arcaicas, assim como no uso de ferramentas agroquímicas avançadas no latifúndio canavieiro, com relações de poder que remetem ao passado escravista.

De fato, o moderno rompe com o tradicional quando o segundo representa um entrave para o avanço do trabalho social dominado pelo capital. Quando o tradicional pode ser absorvido (lucrativo), é (re)feito e dinamizado pelo moderno,com capacidade de absorver seus excedentes. Essas transformações estão associadas aos papéis tradicionais, como osde fornecer mãodeobra e matériasprimas para a cidadee consumir produtos dela oriundos.Porém,o campo abriga cada vez mais atividades não agrícolas, como a produção industrial, os serviços associados às atividades de turismo e a montagem de uma rede de comercialização agrícola associadaàs grandes redes de supermercados. Destarte, buscamos neste trabalho compreender como a interação do tradicional e do moderno atua no processo de comercialização agrícola do estado do Rio de Janeiro, como ocorre a formação de uma nova rede de comercialização associada à antiga,e como o setor mais moderno de produção agrícola absorve a produção e os excedentes dos produtores tradicionais, compreendendo assim permanências e transformações na agricultura fluminense como elementos convergentes.Desse modo, por meio da leitura de referências sobre o tema em tela, de análise de dados censitários e de trabalhos de campo 
realizados com o intuito de complementar as informações de forma qualitativa, procuramos tecer considerações sobre o surgimento de uma nova forma de comercialização da produção agrícola, associada aos hortigranjeiros no estado do Rio de Janeiro.

\section{O papel da tecnologia e do trabalho na conformação de uma nova rede de comercialização agrícola}

Não há dúvidas de que o desenvolvimento tecnológico experimentado pela sociedade nas últimas décadas tem capacidade de melhorar a qualidade de vida do trabalhador como um todo. De fato, a tecnologia poderia realizar tal tarefa se fosse desenvolvida para tal fim; contudo,as transformações técnicas atuais são sempre contextualizadas por necessidades da reprodução do capital.

A precariedade nas relações de trabalho deriva da mesma sociedade capaz de produzir aparelhos de altíssima tecnologia.Uma mesma sociedade é capaz de desenvolver tecnologias fantásticas na área da saúde humana e produzir uma massa de miseráveis sem acesso ao saneamento básico.

A contradição, inerente ao modo de produção capitalista, serve de pista para analisarmos o tradicional e o moderno como uma unidade dos contrários, isto é, a permanência do tradicional é parte do moderno.

O avanço nas técnicas produtivas em nada superou relações sociais arcaicas, como, por exemplo, a exigência cada vez maior do trabalho em detrimento da vida particular. Muitas vezes ocorre justamente o contrário. Nos livros de História, encontramos exemplos que outrora pareciam estranhos e que hoje refletem o cotidiano - as 12 ou 14 horas de trabalho nos primórdios na Revolução Industrial inglesa dos séculos XVIII/XIX não são, em termos quantitativos, uma realidade distante da maioria dos trabalhadores do mundo altamente tecnológico do século XXI.

As ferramentas tecnológicas, poupadoras de trabalho humano, também são instrumentos de controle de eficácia/produtividade do trabalho, elevando bastante os níveis de competitividade entre empresas 
e, consequentemente, entre trabalhadores. Os padrões de eficiência, muitas vezes disfarçados de profissionalismo e responsabilidade, elevam a precariedade do trabalho, a insegurança e os níveis de estresse.

Portanto, as ferramentas tecnológicas capazes de elevar a produtividade dos trabalhadores também são meios de individualização excessiva destes e, como tais, inibem os mecanismos de resistência da classe trabalhadora. Isto gera um caráter contraditório entre a modernização da produção e a precarização das relações de trabalho.Contudo, tais elementos são derivados de um mesmo processo de acumulação de capitais e manutenção do sistema de poder da burguesia.

A realidade de precarização das relações no trabalho não deriva de situações tradicionais de produção, tampouco de realidades históricas ou geográficas distantes dos grandes centros. Tradicional e moderno são elementos unitários e movem-se justamente pela contradição.

No caso da agricultura fluminense, o tradicional está relacionado, em geral, à pequena produção e/ou às relações de poder, enquanto o moderno se estabelece pelo padrão de eficiência/normativo imposto aos produtores (com ou sem capacidade de serem eficientes). Esse processo se estende até a comercialização da produção agrícola,processo no qualesses produtores ficam subordinados aos agentes que efetuam a comercialização, sejam os "atravessadores" tradicionais, que atuam preferencialmente nos postos do CEASA, ou os novos agentes associados às grandes redes, que montam suas plataformas de compra próximo às áreas de produção. Configuram-se,assim, pelo menos duas redes de comercialização, em que se articulam elementos tradicionais como novas formas de comercialização. Essa "nova" rede de comercialização acaba por imprimir novas características ao espaço rural.

O espaço torna-se fortemente marcado pelo conteúdo de técnica e capital, que representa a incorporação dos processos modernos de produção e comercialização, ao mesmo tempo em que mantém as estruturas tradicionais apropriadas pelos elementos modernos/hegemônicos. 
O estado do Rio de Janeiro apresenta, em função do seu alto grau de urbanização,96,7\% de população considerada urbana, conforme a tabela 1, e dificuldades de mecanização de seus solos e expansão imobiliária em decorrência, sobretudo, das atividades turísticas, mais mudanças que permanências no espaço rural fluminense. As permanências seguem o padrão brasileiro de concentração fundiária, precariedade nas relações de trabalho, conflitos pelo acesso à terra. As mudanças associadas à valorização do espaço rural por meio da presença crescente de pessoas oriundas da cidade em busca de áreas de lazer ou de segunda residência, com a valorização das terras e o surgimento de atividades não agrícolas (em geral de baixa qualificação) e que passam a ser ocupadas pelos integrantes das famílias de produtores rurais. Esse elevado grau de urbanização do território fluminense, com concentração na Região Metropolitana.

\begin{tabular}{ccccc}
\hline Ano & Total & Urbana & Rural & Índice (\%) \\
\hline $\mathbf{1 9 5 0}$ & 4674645 & 3392653 & 1281992 & 72,6 \\
$\mathbf{1 9 6 0}$ & 6709891 & 5300629 & 1409262 & 79,0 \\
$\mathbf{1 9 7 0}$ & 8994802 & 7906146 & 1088656 & 87,9 \\
$\mathbf{1 9 8 0}$ & 11291520 & 10368191 & 923329 & 91,8 \\
$\mathbf{1 9 9 1}$ & 12807706 & 12199641 & 608065 & 95,3 \\
$\mathbf{2 0 0 0}$ & 14391282 & 13655386 & 569816 & 94,9 \\
$\mathbf{2 0 1 0}$ & 15989929 & 15464.239 & 525690 & 96,7 \\
\hline
\end{tabular}

Tabela 1. População urbana, rural e índice de urbanização - Rio de Janeiro 1950-2010 Fonte: IBGE - Censos Demográficos, 1950-2010.

Na tabela2, temos uma radiografia da distribuição dos estabelecimentos agrícolas no estado do Rio de Janeiro para os anos de 1996 e 2006.Constata-se que a grande maioria desses estabelecimentos apresenta menos de 100 ha. Em 1996, representavam 75\% e, em 2006, 84\%, o que confere significativa importância à produção familiar e às estratégias que esses agricultores encontram para fazer frente à queda na renda agrícola e ao intenso processo de urbanização. Observa-se, de 1996 a 2006, o aumento do número de estabelecimentos, mas uma pequena diminuição da área ocupada por eles. Constata-se que a estrutura fundiária é marcadamente concentrada no território fluminense. A 
exceção são os municípios da Região Serrana Fluminense, mais especificamente a área chamada “Alto da Serra" (Teresópolis, Petrópolis e Nova Friburgo). O fato de essa região ter tido sua gênese associada a um projeto de colonização agrícola a partir da vinda de imigrantes, aliado às condições desfavoráveis ao desenvolvimento de culturas tropicais, acabou por garantir uma organização do espaço rural caracterizada por um processo de ocupação territorial baseado em pequenas propriedades policultoras. Entre os principais produtos produzidos e comercializados, como indica a tabela3, destacamos o grupo FLV (folhas, legumes e verduras). Apesar da relativa unidade na produção entre os municípios da região, há uma significativa diferença entre as quantidades produzidas nas municipalidades, como aponta o Gráfico 1.

\begin{tabular}{|c|c|c|c|c|}
\hline \multirow[b]{2}{*}{ Grupos de Área } & \multicolumn{2}{|c|}{ Censo Agropecuário 1996} & \multicolumn{2}{|c|}{ Censo Agropecuário 2006} \\
\hline & $\begin{array}{c}\text { Número de } \\
\text { estabelecimentos }\end{array}$ & Área & $\begin{array}{c}\text { Número de } \\
\text { estabelecimentos }\end{array}$ & Área \\
\hline Menos de 10 ha & 3.962 & 14.293 & 5.275 & 16.667 \\
\hline $\begin{array}{c}10 \text { a menos de } \\
100 \text { ha }\end{array}$ & 13.647 & 659.266 & 14.384 & 653.596 \\
\hline $\begin{array}{c}100 \text { a menos de } \\
1000 \text { ha }\end{array}$ & 5.860 & 1.247 .891 & 7.572 & 1.667 .703 \\
\hline 1000 ha e mais & 319 & 1.261 .615 & 376 & 1.153 .317 \\
\hline $\begin{array}{c}\text { Sem info ou sem } \\
\text { área }\end{array}$ & 0 & -------------- & 1.875 & ------------- \\
\hline Total & 23.788 & 0 & 29.482 & 3.491 .283 \\
\hline
\end{tabular}

Tabela 2. Estabelecimentos agrícolas do estado do Rio de Janeiro - 1996-2006. Fonte: IBGE - Censos Agropecuários, 1996-2006. 


\begin{tabular}{|c|c|c|}
\hline Município & Produtos da horticultura & Quantidade produzida \\
\hline \multirow{3}{*}{ Bom Jardim - RJ } & Inhame (Toneladas) & 9.086 \\
\hline & Tomate (estaqueado) (Toneladas) & 6.865 \\
\hline & Batata-doce (Toneladas) & 4.708 \\
\hline Cantagalo - RJ & Quiabo (Toneladas) & 12 \\
\hline \multirow{3}{*}{ Carmo - RJ } & Abobrinha (Toneladas) & 188 \\
\hline & Berinjela (Toneladas) & 146 \\
\hline & Pepino (Toneladas) & 110 \\
\hline Cordeiro - RJ & Sem dados & \\
\hline \multirow{3}{*}{ Duas Barras - RJ } & Tomate (estaqueado) (Toneladas) & 566 \\
\hline & Chuchu (Toneladas) & 277 \\
\hline & Jiló (Toneladas) & 249 \\
\hline \multirow{3}{*}{ Nova Friburgo - RJ } & Tomate (estaqueado) (Toneladas) & 13.026 \\
\hline & Couve-flor (Toneladas) & 8.894 \\
\hline & Repolho (Toneladas) & 3.560 \\
\hline \multirow{3}{*}{ Petrópolis - RJ } & Alface (Toneladas) & 3.921 \\
\hline & Chuchu (Toneladas) & 2.036 \\
\hline & Couve (Toneladas) & 1.125 \\
\hline $\begin{array}{c}\text { Santa Maria Madalena - } \\
\text { RJ }\end{array}$ & Alface (Toneladas) & 12 \\
\hline \multirow{3}{*}{$\begin{array}{c}\text { São José do Vale do Rio } \\
\text { Preto - RJ }\end{array}$} & Chuchu (Toneladas) & 16.955 \\
\hline & Tomate (estaqueado) (Toneladas) & 9.276 \\
\hline & Couve-flor (Toneladas) & 1.897 \\
\hline \multirow{3}{*}{ Sumidouro - RJ } & Tomate (estaqueado) (Toneladas) & 18.698 \\
\hline & Alface (Toneladas) & 15.927 \\
\hline & Repolho (Toneladas) & 7.784 \\
\hline \multirow{3}{*}{ Teresópolis - RJ } & Alface (Toneladas) & 114.925 \\
\hline & Agrião (Toneladas) & 40.690 \\
\hline & Brócolis (Toneladas) & 27.968 \\
\hline \multirow{3}{*}{ Trajano de Moraes - RJ } & Tomate (estaqueado) (Toneladas) & 2.668 \\
\hline & Inhame (Toneladas) & 1.887 \\
\hline & Repolho (Toneladas) & 900 \\
\hline
\end{tabular}

Tabela 3. Produção de horticultura (2006) - principais produtos - Região Serrana.

Fonte: IBGE - Censo Agropecuário 2006. 


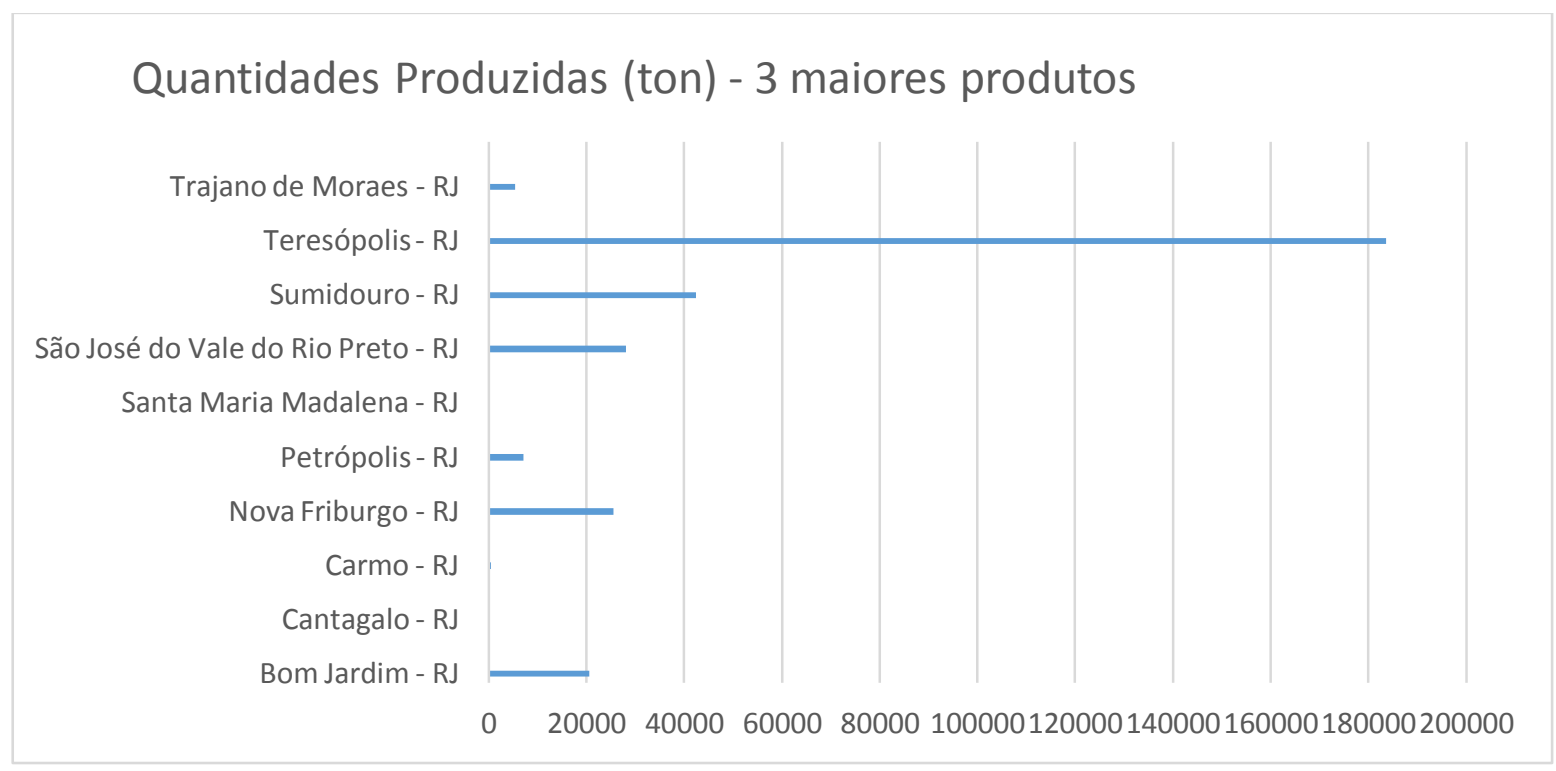

Gráfico 1. Produção (t) dos municípios da Região Serrana (2006).

Fonte: IBGE - Censo Agropecuário 2006

O município de Teresópolis destaca-se na quantidade produzida e, por isso, centraliza os principais operadores logísticos para comercialização da região. Na verdade, a presença/centralização de diferentes entrepostos de comercialização explicita as diferentes redes de comercialização. Há redes entrecruzadas com funcionalidades distintas, ou seja, a produção da Região Serrana atende a redes com diferentes parâmetros de eficiência e normativos (relativos a prazo e qualidade, por exemplo) que articulam produtores com diferentes graus de capitalização e modernização.

Portanto, o moderno e o atrasado não representam um par dicotômico. Interagem e, além disso, são mutuamente dependentes. Os operadores logísticos de maior capacidade técnica e normativa dependem, por vezes, dos produtores com baixo grau de modernização e integração nas redes de comercialização dos principais varejistas da Região Metropolitana.

\section{O moderno e o tradicional na rede de comercialização agrícola no Rio de Janeiro}

O padrão reticular do espaço pressupõe a conexão de áreas não contínuas, promovendo a circulação e a comunicação de produtos, mercadorias, informações, enfim, a articulação entre dois ou mais nós é condição essencial para a gênese das redes (DIAS, 2001; SANTOS, 2002). 
As redes geográficas, ao tratar dos fluxos e dos fixos (SANTOS, 2002) associados ao movimento pelo espaço, tornam-se um instrumental conceitual e analítico fundamental para o estudo do sistema de abastecimento de gêneros agrícolas, afinal há a formação de rede(s) para viabilizar as interações espaciais entre produtores e consumidores (CORRÊA, 1997).

As articulações inseridas na espacialidade reticular, segundo Corrêa (1997), são produtoras de diferenciação espacial por integrar e marginalizar variados nós constantemente.Para esse autor, o movimento dos fluxos requer e orienta a produção de fluidez espacial, porém a gênese e a gestão do fluxo requerem a territorialização dos fixos (HAESBAERT, 2004).

A capacidade da configuração reticular (por redes) de articular espaços de produção é uma característica peculiar e importante para o argumento central outrora exposto, ou seja, a produção simultânea e integrada do moderno e do tradicional. No caso da agricultura, a produção tradicional, cercada por técnicas ultrapassadas e relações trabalhistas de semiservidão,é incorporada por cadeias logísticas (em rede) de extrema capacidade técnica.

No sentido proposto por Santos (2002), as redes geográficas, ao garantir maior fluidez espacial, fomentam o curso da comercialização de mercadorias, tão fundamental quanto o próprio processo produtivo. De fato, como indica Novaes (2004), a circulação de peças e mercadorias finalizadas é a próxima fronteira de redução de custos para o capital. Para o autor,

\footnotetext{
Um produto que saia da fábrica, digamos, a um preço de US\$1, acaba sendo vendido por US\$4 nas lojas do varejo. Reduzir os custos de produção de 10 ou 20 centavos de dólar é uma tarefa quase impossível hoje, pois todo mundo vem trabalhando nessa direção há tempo, e não há muito mais gordura a ser queimada. Ou seja, e esse US\$1 é a parte hard do custo global. É melhor atacar os custos que se distribuem ao longo da cadeia - que constituem os chamados 3 dólares soft (NOVAES, 2004, p. 65).
}

A logística - todo o aparato técnico associado ao transporte e à organização da produção - é transformada em diferencial competitivo e instrumento de agregação de valor. A centralidade da logística está associada ao padrão reticular e, consequentemente, à fluidez espacial, aos fluxos e à 
localização dos fixos. O diferencial logístico leva ao processo de especialização e terceirização, isto é, ao surgimento de empresas focadas em reduzir custos logísticos e promover o just in time, agregando valor à gestão dos fluxos na cadeia de suprimentos.

Essas transformações socialmente construídas são resultados dialéticos, segundo Soja (1993). Para o autor, "os dois conjuntos de relações estruturadas (o social e o espacial) são não apenas homólogos, no sentido de provirem das mesmas origens no modo de produção, como também dialeticamente inseparáveis" (p. 99). Logo, o padrão reticular está inserido na dinâmica do capital, com inserções, marginalizações, expansão, resistência, consentimentos, hegemônicas e hegemonizadas e transformações e permanências, substituição e convívio. Logo, as redes não eliminam a espacialidade zonal, mas contribuem para (re)dinamizar as horizontalidades historicamente processadas.

O processo histórico de (re)produção do espaço, de acordo com Santos (2002), também está previsto para o padrão reticular. Há, como lembra o autor, uma relação entre a difusão e o incremento técnico e o avanço das redes geográficas. Diz Santos (2002):

\footnotetext{
Se compararmos as redes do passado com as atuais, a grande distinção entre elas é a respectiva parcela de espontaneidade na elaboração respectiva. Quanto mais avança a civilização material, mais se impõe o caráter deliberado na constituição de redes. Com os recentes progressos da ciência e da tecnologia e com as novas possibilidades abertas à informação, a montagem das redes supõe uma antevisão das funções que poderão exercer e isso tanto inclui a sua forma material, como as suas regras de gestão (p. 265).
}

O conjunto técnico disponível no atual momento, conhecido como globalização, enseja a maior troca de informações, a mais precisa troca de mercadorias e serviços e a circulação de capitais de forma imaterial e instantânea. A velocidade e a busca por fluidez são imperativos sociais, econômicos e espaciais ocasionados pelo dinamismo tecnológico do momento atual, agindo de forma indiscriminada no campo e na cidade.

Seguindo com Santos (2002), o arranjo espacial em rede, além de expressar uma configuração, é um instrumento de poder, via, particularmente, gestão dos fluxos, pois a circulação é controlada por fixos previamente selecionados. Destarte, compreende-se a gestão da cadeia de suprimentos como uma 
expressão hegemônica dos agentes com maior capacidade técnica e econômica, justamente por sua capacidade de estabelecer as regras, ou seja, a normatização do padrão de competividade.

A tecnologia de transportes e de telecomunicações é um alicerce para a configuração das redes geográficas, apesar de não ser responsável por sua gênese. A construção histórica e espacial do arranjo reticular absorve a construção da necessidade de fluidez, da flexibilidade e dos parâmetros competitivos como falso consenso social, impactos na produção, na circulação e no consumo.

É inseparável, então, analisar as transformações no arranjo espacial e na criação de parâmetros competitivos sem analisar as alterações em curso (construídas) na esfera do consumo. Isso posto, recorre-se a Canclini (2001) para reconhecer a racionalidade do consumo, ou seja, "o consumo é um processo em que os desejos se transformam em demandas e em atos socialmente regulados" (p. 77).

Os fluxos, além de mercadorias e normas, também incorporam valores desejados, criando, no sentido consumidor-produtor, uma circulação fundamental para determinar preço, prazo e qualidade da produção. De fato, como afirma Canclini (2001), o consumidor é socialmente regulado e, portanto, o consumo não representa desejos desconectados da conjuntura técnico-produtivo-espacial.

Peci (1999), tecendo conexões entre produção, circulação e consumo no ambiente empresarial, observa na flexibilidade uma categórica orientação para as cadeias de suprimentos. Na prática, a demanda é diversificada; em outras palavras, há solicitações distintas dos diversos nichos de mercado e, por isso, a produção precisa ser ágil para atender às necessidades originárias na demanda.

O padrão reticular é fundamental para fecundar processos flexíveis de produção e distribuição, incorporando ou segregando, de forma dinâmica, nós capazes de atender ao imperativo do consumo em cada conjuntura e para cada lugar.

As interações transescalares são inevitáveis para o processo produtivo e, como aponta Canclini (2001), para o estabelecimento de normas também no consumo. Conforme comenta o autor, 
A metrópole cria padrões de uniformidade, remodela os hábitos locais e os subordina. Contudo a homogeneização do consumo e da sociabilidade, propiciada pelo formato comum com que esses serviços se organizam, não anula as particularidades (CANCLINI, 2001, p. 99).

Em outro momento, Canclini (2007) critica a construção de padrões e de normas flexíveis para os processos produtivos por empresas transnacionais, ao mesmo tempo em que as relações com o produtor-trabalhador são inapelavelmente rígidas. Para o autor,

\footnotetext{
Na verdade, o que se torna instável, mais do que flexível, são as condições de trabalho; o trabalho é rígido porque é incerto, o trabalhador precisa cumprir à risca os horários, os rituais de submissão, a adesão a uma ordem alheia que acaba sendo interiorizada para não perder o salário (CANCLINI, 2007, p. 24)
}

Na Região Serrana, por exemplo, os produtores atuam como nós (sob o dinâmico regime de inclusão/marginalização) de diversas redes de abastecimento da área metropolitana. Parceiros ou proprietários, pouco importa nesse caso; são fornecedores (terceirização) de operadores logísticos integrados, em geral, às grandes redes varejistas. Dessa forma, são submetidos ao arsenal normativo e técnico (às urbanidades) dos supermercados e dos consumidores, representando, assim, a integração de elementos materiais (a produção agrícola) e imateriais (as normas e as ações).

Todavia, como aponta o próprio Canclini (2007), as imposições são emaranhadas de resistências e consentimentos e, consequentemente, as ações hegemônicas na globalização simultaneamente reforçam as particularidades e a coexistência do local.

A mobilidade do capital configurado por redes em (re)produtor da espacialidade reticular, sem apagar o passado do espaço, torna vitoriosa a empresa integrada aos parâmetros técnicos atuais, com mais condições de gerenciar os fluxos, mais capacidade de produzir de forma flexível e sempre preparada (e capitalizada) para reestruturações no aspecto organizacional.

As grandes empresas transnacionais do varejo constituem a vanguarda logística na gestão dos fluxosredes na distribuição de gêneros agrícolas. A comercialização agrícola no estado do Rio de Janeiro tem nos supermercados o seu agente hegemônico, em virtude da assimetria de poder entre varejistas, operadores logísticos e produtores familiares. 
Nesse sentido, Haesbaert (2004) relaciona o controle dos fluxos articulados por redes e poder. De acordo com o autor,

Como as informações "fluem" através de redes cuja materialidade na maioria das vezes se restringe a pontos de conexão como os chamados teleportos, exige-se o domínio destas conexões, bem como das "senhas" de acesso às redes. A principal forma de controle ou de influência nesses territórios-rede se dá através destes pontos de acessibilidade, embora também possamos encontrar interferências, mais raras, relacionadas diretamente à intermediação dos fluxos em sentido mais estrito (HAESBAERT, 2004, p. 302).

Além de relacionar o controle dos fluxos e do acesso às redes, a citação indica a articulação da mobilidade - das interações espaciais - com o processo de territorialização. 0 território em Haesbaert (2004) é também movimento e, assim, fluxo e rede são inseparáveis, afastando uma oposição entre eles. Como lembra o autor,

\footnotetext{
O problema é que muitos autores, geógrafos e não geógrafos, fazem uma leitura a nosso ver dicotômica entre territórios e redes, como se fossem duas unidades distintas e mesmo antagônicas, não percebendo nem mesmo que rede pode ser vista como um elemento constituinte do território. (HAESBAERT, 2004, p. 282)
}

A contribuição do autor, também a partir de Haesbaert (2005), é fundamental para relacionar a análise da comercialização agrícola às múltiplas territorialidades em disputa, ou seja, às normas e aos padrões em disputa que, mesmo de forma assimétrica, manifestam múltiplos territórios e garantem, contextualizados pelas formas de resistência, cooptação, consentimento e experiência da multiterritorialidade para os pequenos produtores familiares.

Na mesma linha, Coelho Neto (2013), seguindo a concepção do território como dinâmica social, sugere a territorialização em áreas não contínuas e a possibilidade de sobreposição dos territórios. Assim como Haesbaert (2004; 2005), o autor entende a construção de territórios-rede acionando múltiplas escalas, múltiplos territórios e "superposição de territorialidades" (COELHO NETO, 2013, p. 29).

Assim, em relação à comercialização agrícola, os produtores são inseridos e marginalizados, incluídos ou não nos múltiplos territórios integrados em rede. Os "de dentro e os de fora" afetam e influenciam 
as práticas de comercialização, ou seja, produzem territorialidades harmônicas e/ou conflitantes, experimentam diversas formas de comercialização e constroem laços com distintos operadores logísticos.Por isso, (re)criam inúmeras estratégias de reprodução social e espacial, explicitam o convívio e a produção conjunta do tradicional e do moderno.

As várias estratégias de sobrevivência tornam mais complexa a espacialização da rede de comercialização agrícola fluminense, estabelecendo uma equação dinâmica para a assimetria de poder em jogo. A lógica binária hegemônica x hegemonizado representa a simplificação de interações sociais com inúmeras e efêmeras posições e participações. A territorialidade dos agentes envolvidos no abastecimento é "uma rede complexa" (SOUZA, 2001, p. 92)que integra os diversos nós realizadores de funções distintas e que disputa o controle sobre os fluxos.

Em sintonia com as referências anteriormente citadas, Dias (2010) recupera a escala geográfica como mais um componente desse tecido-linhas, construindo as relações sociais envolvidas nas diferentes escalas e, principalmente, nos contatos entre territórios-redes pela lógica transescalar. As escalas são constantemente reelaboradas e a equação da assimetria de poder ganha novos pesos e novas variáveis e, de acordo com a autora, a atuação transescalar de alguns agentes ainda tem o maior peso.

As redes e os fluxos são basilares da globalização econômica por produzirem interdependência entre os lugares, entre os lugares e as técnicas, entre as técnicas e o conhecimento e entre o conhecimento e o poder. As demandas de produção e de circulação de bens, mercadorias e informações implicam a formação de laços, possivelmente desatados, entre os nós da rede. Isso posto, Corrêa (1997) ratifica as redes geográficas como o meio fundamental para viabilizar as interações espaciais.

Ribeiro (1998), Corrêa (1997) e Santos (2002), por certo, entrelaçam fixos e fluxos e organização espacial em redes e a transformação do território. Santos (2002) desvenda os movimentos das redes pela produção de desigualdades e, complementado por Ribeiro (1998), pela geração de hierarquias e especializações marcadas pela brevidade. Nas palavras de Santos (2002), 
O problema é que muitos autores, geógrafos e não geógrafos, fazem uma leitura a nosso ver dicotômica entre territórios e redes, como se fossem duas unidades distintas e mesmo antagônicas, não percebendo nem mesmo que rede pode ser vista como um elemento constituinte do território. (HAESBAERT, 2004, p. 282)

A contribuição do autor, também a partir de Haesbaert (2005), é fundamental para relacionar a análise da comercialização agrícola às múltiplas territorialidades em disputa, ou seja, às normas e aos padrões em disputa que, mesmo de forma assimétrica, manifestam múltiplos territórios e garantem, contextualizados pelas formas de resistência, cooptação, consentimento e experiência da multiterritorialidade para os pequenos produtores familiares.

Na mesma linha, Coelho Neto (2013), seguindo a concepção do território como dinâmica social, sugere a territorialização em áreas não contínuas e a possibilidade de sobreposição dos territórios. Assim como Haesbaert (2004; 2005), o autor entende a construção de territórios-rede acionando múltiplas escalas, múltiplos territórios e "superposição de territorialidades" (COELHO NETO, 2013, p. 29).

Assim, em relação à comercialização agrícola, os produtores são inseridos e marginalizados, incluídos ou não nos múltiplos territórios integrados em rede. Os "de dentro e os de fora" afetam e influenciam as práticas de comercialização, ou seja, produzem territorialidades harmônicas e/ou conflitantes, experimentam diversas formas de comercialização e constroem laços com distintos operadores logísticos.Por isso, (re)criam inúmeras estratégias de reprodução social e espacial, explicitam o convívio e a produção conjunta do tradicional e do moderno.

As várias estratégias de sobrevivência tornam mais complexa a espacialização da rede de comercialização agrícola fluminense, estabelecendo uma equação dinâmica para a assimetria de poder em jogo. A lógica binária hegemônica $\mathrm{x}$ hegemonizado representa a simplificação de interações sociais com inúmeras e efêmeras posições e participações. A territorialidade dos agentes envolvidos no abastecimento é "uma rede complexa" (SOUZA, 2001, p. 92)que integra os diversos nós realizadores de funções distintas e que disputa o controle sobre os fluxos. 
Em sintonia com as referências anteriormente citadas, Dias (2010) recupera a escala geográfica como mais um componente desse tecido-linhas, construindo as relações sociais envolvidas nas diferentes escalas e, principalmente, nos contatos entre territórios-redes pela lógica transescalar. As escalas são constantemente reelaboradas e a equação da assimetria de poder ganha novos pesos e novas variáveis e, de acordo com a autora, a atuação transescalar de alguns agentes ainda tem o maior peso.

As redes e os fluxos são basilares da globalização econômica por produzirem interdependência entre os lugares, entre os lugares e as técnicas, entre as técnicas e o conhecimento e entre o conhecimento e o poder. As demandas de produção e de circulação de bens, mercadorias e informações implicam a formação de laços, possivelmente desatados, entre os nós da rede. Isso posto, Corrêa (1997) ratifica as redes geográficas como o meio fundamental para viabilizar as interações espaciais.

Ribeiro (1998), Corrêa (1997) e Santos (2002), por certo, entrelaçam fixos e fluxos e organização espacial em redes e a transformação do território. Santos (2002) desvenda os movimentos das redes pela produção de desigualdades e, complementado por Ribeiro (1998), pela geração de hierarquias e especializações marcadas pela brevidade. Nas palavras de Santos (2002),

Num mesmo subespaço, há uma superposição de redes, que inclui redes principais e redes afluentes ou tributárias, constelações de pontos e traçados de linhas. Levando em conta seu aproveitamento social, registram-se desigualdades no uso e é diverso o papel dos agentes no processo de controle e de regulação do seu funcionamento (p. 268).

Reardon e Berdegué (2003) são frutíferos produtores de exemplos dos mecanismos anteriormente apresentados a partir da atuação dos supermercados. Entendidos como centralidade, os supermercados, via operadores logísticos, selecionam produtores capazes de atender à demanda cotidiana das filiais e, na outra vertente, elegem as áreas para alocar suas filiais ao escolherem o perfil do consumidor.

Além dessas interações básicas, as redes varejistas são atuantes em redes sobrepostas e de caráter transescalar, influindo de forma transversal nas múltiplas escalas e redes. Tal afirmação converge com Santos (2002),ao considerar que "as redes seriam incompreensíveis se apenas enxergássemos a partir 
de suas manifestações locais ou regionais. Mas estas são também indispensáveis para entender como trabalham as redes à escala do mundo". Portanto, para Santos (2002b),

Daí porque o fundamento de uma teoria que deseje explicar as localizações específicas deve levar em conta as ações do presente e do passado, locais e extralocais. O lugar assegura assim a unidade do contínuo e do descontínuo, o que a um tempo possibilita sua evolução e também lhe assegura uma estrutura concreta inconfundível (p. 258).

O imperativo do par indissociável técnica-fluidez engendra, segundo Dias (2005), a construção de padrões de eficiência que, retomando a citação de Santos (2002b), encontram entraves e potencialidades de acordo com o conjunto de relações hodiernas e pretéritas, horizontais e verticais, produtores da idiossincrasia de cada lugar.

As múltiplas influências produtoras de desigualdades e particularidades são intensificadas pelo atual estágio de internacionalização do modo de produção capitalista - a globalização. Redes,escala e globalização alteram generalidades e interagem com especificidades, (re)criando símbolos, lugares, práticas sociais e técnicas.

Santos (2000) avalia a globalização como um momento de ampliação máxima do modo de produção capitalista, com múltiplas formas e resultados variados. Distante de apreender a totalidade do processo, é fundamental qualificá-la como plural, ou seja, como globalizações para os processos articulados nas escalas mais amplas e, principalmente, para os resultados nos lugares.

A pluralidade do presente nas globalizações não evita, como lembra Santos (2000), a configuração de centros restritos de comando das ações, essencialmente da difusão de inovações técnicas e organizacionais. De fato, as redes articulam inúmeros nós, porém poucos são capazes de gerenciar os fluxos em circulação.

No contexto plural da globalização, das redes geográficas e da construção de novos parâmetros de eficiência e produtividade (flexibilidade), a ação de grandes redes varejistas, como aponta Wilkinson (2003), revela um mecanismo de interação transescalar contextualizado pela globalização. Para o 
autor, a principal alteração em curso é "uma transformação do ambiente concorrencial que leva a maiores níveis de eficiência e a pressões tanto sobre custos quanto sobre um maior ritmo de inovações e modernização tecnológica" (p. 67).

Continuando com os argumentos do autor, ressalta-se o impacto das mudanças no ambiente empresarial. Há alteração na escala competitiva, agora de caráter global, para as instituições nacionais em atuação no varejo e, logo, na comercialização agrícola. Essa conjuntura edifica critérios técnicos e organizacionais para os produtores e para os sistemas logísticos de distribuição dos gêneros agrícolas.

Nesse contexto, as principais transformações passam pelo fortalecimento de sistemas de terceirização de operadores logísticos e pela requalificação da centralidade do sistema CEASA-RJ. Em relação aos primeiros, há, no circuito Tere-Fri, o surgimento de várias empresas de transporte e agregação de valor de produtos rurais responsáveis pelo abastecimento de varejistas localizados na área metropolitana. Em relação ao segundo, o CEASA-Rio, localizado no bairro de Irajáda capital fluminense, mantém um papel na distribuição de produtos para feiras, algumas redes varejistas e comerciantes de menor porte.

Os impactos das globalizações para a comercialização atuam, basicamente, na transformação das técnicas logísticas e nos arranjos organizacionais - na relação entre empresas, controle de estoques e oferta de produtos. A manutenção de um fluxo de abastecimento para as filiais das redes varejistas determina um arranjo espacial e técnico gerador de novas territorialidades e temporalidades para os produtores familiares. A fluidez espacial e a aceleração do processo produtivo motivam os processos de inclusão/marginalização e, consequentemente, as múltiplas estratégias de ação (territorialidades).

Santos (2000) exalta a multiplicidade presente nas globalizações, seus efeitos espaciais resultantes e 0 convívio do diferente. Como nota o autor,

Criam-se, paralelamente, incompatibilidades entre velocidades diversas; e os portadores das velocidades extremas buscam induzir os demais atores a acompanhá-los, procurando disseminar as infraestruturas necessárias à desejada fluidez nos lugares que consideram necessários para a 
sua atividade. Há, todavia, sempre, uma seletividade nessa difusão separando os espaços da pressa daqueles outros propícios à lentidão (SANTOS, 2000, p. 84).

A presença hegemônica da técnica e da construção de hegemonias não elimina a diversidade presente no lugar e, da mesma forma, os movimentos opostos à racionalidade externa - verticalidades oriundas do processo de globalização - não inviabilizam a presença de atores hegemônicos. Na prática, com o auxílio de Santos (2000; 2002; 2005; 2007), entende-se a existência de inúmeras variáveis e troca de papéis na rede de comercialização agrícola no Estado do Rio de Janeiro.

A expansão e a reprodução ampliada do capital, sob a égide da globalização, fomentam o desenvolvimento de tecnologias. Logo, compreender a configuração reticular da comercialização agrícola passa por reconhecer na dinâmica realizada no estado do Rio de Janeiro marcas, formas e ações inseridas por interações com outras escalas e temporalidades.

O papel das verticalidades é considerado sem exclusão dos encaixes socioespaciais realizados historicamente no plano horizontal. As ações verticais explicam e promovem a interpendência dos agentes envolvidos na comercialização e a ação transescalar atuante nas redes sobrepostas. A espacialidade resultante será sempre um resultado em processo, uma combinação desigual de tempos e escalas.

Santos (2005) renova a relação íntima e necessária entre a (re)produção do espaço e o modo de produção hegemônico. Para o autor,

Quando se fala de modo de produção, não se trata simplesmente de relações sociais que tomam uma forma material, mas também de seus aspectos imateriais, como o dado político ou ideológico. Todos eles têm uma influência determinante nas localizações e tornam-se assim um fator de produção, uma força produtiva, com os mesmos direitos que qualquer outro fator (SANTOS, 2005, p. 32).

De acordo com a citação, o capital é categorizado para além da produção e incorpora, dialeticamente, sociedade e espaço. Logo, as expressões materiais e imateriais estão presentes na espacialidade e, consequentemente, esta apresentará contornos para além das formas tangíveis. 
Com efeito, não há objetos cristalizados na paisagem, pois, intensamente, há substituição de formas e/ou de funções (SANTOS, 2012). Como indica Harvey (2005),

A acumulação é o motor cuja potência aumenta no modo de produção capitalista. $\mathrm{O}$ sistema capitalista é, portanto, muito dinâmico e inevitavelmente expansível; esse sistema cria uma força permanentemente revolucionária, que, incessante e constantemente, reforma o mundo em que vivemos (p. 43).

A acumulação ampliada e a alocação dos excedentes explicam, em parte, as transformações contínuas no arranjo socioespacial a fim de viabilizar novos espaços para investimentos. A construção de novos ou a reinvenção de antigos mecanismos de circulação e ampliação é necessária porque existe um contínuo incremento no volume de capital disponível para o investimento. Como indica Marx (2013),

Não devemos esquecer que, ao lado dos novos capitais, continua o capital primitivo a se reproduzir e a produzir mais-valia e que o mesmo é verdade para cada capital acumulado em relação ao capital adicional que produziu (p. 381).

Seguindo essa linha, os momentos de crise revelam o esgotamento de possibilidades para a circulação e, simultaneamente, a busca por novos processos. Assim, as (re)configurações espaciais, como a construção da acumulação flexível e a espacialidade reticular, também indicam a apropriação/adequação de formas e funções de acordo com as necessidades de acumulação de cada conjuntura histórica.

Entretanto, a crise, além de criar oportunidades de investimentos, é acompanhada de transformações sociais. Harvey (2005) declara que,

Como não há outras forças compensatórias em ação dentro da anarquia do sistema econômico capitalista, as crises possuem uma função importante: elas impõem algum tipo de ordem e racionalidade no desenvolvimento econômico capitalista. Isso não quer dizer que as crises sejam ordenadas ou lógicas; de fato, as crises criam as condições que forçam a algum tipo de racionalização arbitrária no sistema de produção capitalista. Essa racionalização apresenta um custo social e provoca trágicas consequências humanas na forma de falências, colapsos financeiros, desvalorização forçada de ativos fixos e poupanças pessoais, inflação, concentração crescente de poder econômico e político em poucas mãos, queda de salários reais e desemprego (p. 46 e 47).

Transpondo essa análise para a perspectiva de Santos (2012), as redes geográficas e as verticalidades (transescalaridade) convivem com espacialidades zonais e horizontalidades. Contudo, "as redes 
constituem apenas uma parte do espaço" (p. 139) e, nesse sentido, a atuação seletiva do padrão reticular representa apropriação (efêmera ou não) de formas e/ou de funções previamente estabelecidas.

Santos (2012) afirma que a probabilidade de apropriação de uma forma ou de uma função manifesta a possibilidade de retorno e lucro daquela particularidade. Logo, sem esquecer o acontecer global, "a democracia de mercado e o neoliberalismo" (SANTOS, 2012, p. 142) se apropriam de funções outrora coletivas, estatais ou solidárias, construindo relações assimétricas de poder e parâmetros competitivos para antigas formas e/ou funções.

O mesmo autor, tratando de processos de apropriação de determinados lugares, sugere a diferenciação entre a produção do espaço e a produtividade do espaço. Para Santos (2012),

Podemos falar de produtividade espacial, noção que se aplica a um lugar, mas em função de uma atividade ou conjunto de atividades. Essa categoria se refere mais ao espaço produtivo que ao produzido. Sem minimizar a importância das condições naturais, são as condições artificialmente criadas que sobressaem, enquanto expressão dos processos técnicos e dos marcos espaciais da informação (p. 149).

Neste trabalho, entendem-se as transformações na base técnica em curso na produção e na comercialização agrícola da área serrana também como mudança na conjuntura política e econômica. Portanto, no arranjo socioespacial, a espacialidade reticular é consequência técnica, política e econômica.

Na prática, Santos (2007) separa a produção e a produtividade dos espaços para, em seguida, unificálos pelo trabalho humano, isto é, centraliza as relações socioespaciais e as assimetrias de poder via trabalho, e não por meio das técnicas e da racionalidade absoluta. Segundo o autor,

A estrutura técnico-produtiva não é o espaço produtivo. Esse é o resultado da utilização efetiva da estrutura técnico-produtiva para responder aos objetivos das classes dominantes, dentro de uma formação socioeconômica (SANTOS, 2007, p. 84). 
O trabalho social (MARX, 2013) “cristaliza" valor na mercadoria e é justamente da circulação e da comercialização que a (re)produção social do capital se realiza na plenitude. A incorporação de valor à mercadoria passa, nessa leitura, pela quantidade de trabalho social necessário para a produção da mercadoria em um determinado contexto técnico e pelas relações entre as forças produtivas e as classes hegemônicas.

Logo, ao falar do contexto técnico-logístico, na verdade, destaca-se o resultado das necessidades criadas ou pensadas socialmente e dialeticamente relacionadas com (re)produção do espaço. Santos (2002) clarifica tal relação ao estabelecer que "cada período técnico é portador de um sentido, partilhado pelo espaço e pela sociedade" (p. 171).

Desiguais e irrevogáveis, a atuação e a expansão das técnicas engendram novas relações históricas, sociais, espaciais e escalares. Assim, as ramificações e as construções nas horizontalidades e verticalidades tornam-se procedimentos essenciais na (re)produção do espaço. Elementos endógenos e exógenos atuam com pesos diferentes ao longo do tempo e do espaço, servindo de promotores e construtores de relações viabilizadas pelo padrão reticular, entre histórias próximas e distantes.

Santos (2002) relaciona esse conteúdo técnico ao próprio cotidiano das relações socioespaciais, justificando o caráter irreversível desse processo. Segundo o autor,

Ainda que fosse possível abandonar algumas técnicas como modo de fazer, permanecem aquelas que se impuseram com o modo de ser, incorporadas à natureza e ao território, como paisagem artificial. Neste sentido elas são irreversíveis, na medida em que, em um primeiro momento, são um produto da história, e, em um segundo momento, elas são produtoras da história, já que diretamente participam desse processo (SANTOS, 2002, p. 181).

A técnica e o discurso da eficiência são estruturantes da lógica flexível e reticular presente na comercialização agrícola e, consequentemente, nas relações sociais e na dinâmica do abastecimento de gêneros agrícolas. Em conjunto, essas produções orientam uma relação de controle e também de embate dentro das relações de produção, ou seja, tempo e espaço são construções sociais orientadas por técnicas e normas produtivas. 
Destarte, em um quadro de assimetria de poder, as construções são resultado de múltiplas forças e processos sociais. Entretanto, a orientação essencial da espacialidade da comercialização agrícola indica a liderança das grandes redes varejistas de ação transescalar. De acordo com Santos (2005),

\begin{abstract}
Mas só os atores hegemônicos se servem de todas as redes e utilizam todos os territórios. Eis por que os territórios nacionais se transformaram num espaço nacional da economia internacional e os sistemas de engenharia criados em cada país podem ser mais bem utilizados por firmas transnacionais do que pela própria sociedade nacional (p. 150).
\end{abstract}

Vale destacar que a hegemonia e as pressões exógenas ampliam diferenças, desigualdades e complexidades nos lugares. As redes geográficas se apropriam de áreas de interesse do capital sem, contudo, destruirem movimentos de contraespaço (MOREIRA, 2011; 2012). As formas de regulação e normatização das práticas cotidianas não seguem os aspectos lineares e retilíneos dos padrões de eficiência, produtividade e organização empresarial, (re)criando e (re)processando formas, processos e funções em todas as escalas (SANTOS, 2012).

O Figura 1, a seguir, indica um dos formatos para a configuração da cadeia de suprimentos dentro da perspectiva de controle de vulnerabilidade e ampliação da eficiência. Os operadores logísticos são mais eficientes no reconhecimento de produtores, na organização da coleta dos produtos e na distribuição para os supermercados/varejistas. Os varejistas não recorrem a um único operador logístico também para reduzir riscos de desabastecimento. A redundância ainda é uma realidade para a rede de abastecimento de gêneros agrícolas na Região Serrana em virtude da maior imprevisibilidade da produção e, em menor grau, do consumo, graças aos mecanismos informacionais de controle da demanda.

Da mesma forma que os operadores logísticos atuam com um número de produtores maior do que a necessidade usual (controlada pela demanda dos varejistas), os produtores buscam inserir-se em diversas redes de comercialização. Entretanto, há uma enorme diferença entre o número de articulação que um agente consegue estabelecer, isto é, os produtores (exceto em momentos de elevadíssima demanda) ficam subordinados às estratégias dos operadores logísticos/atravessadores. 


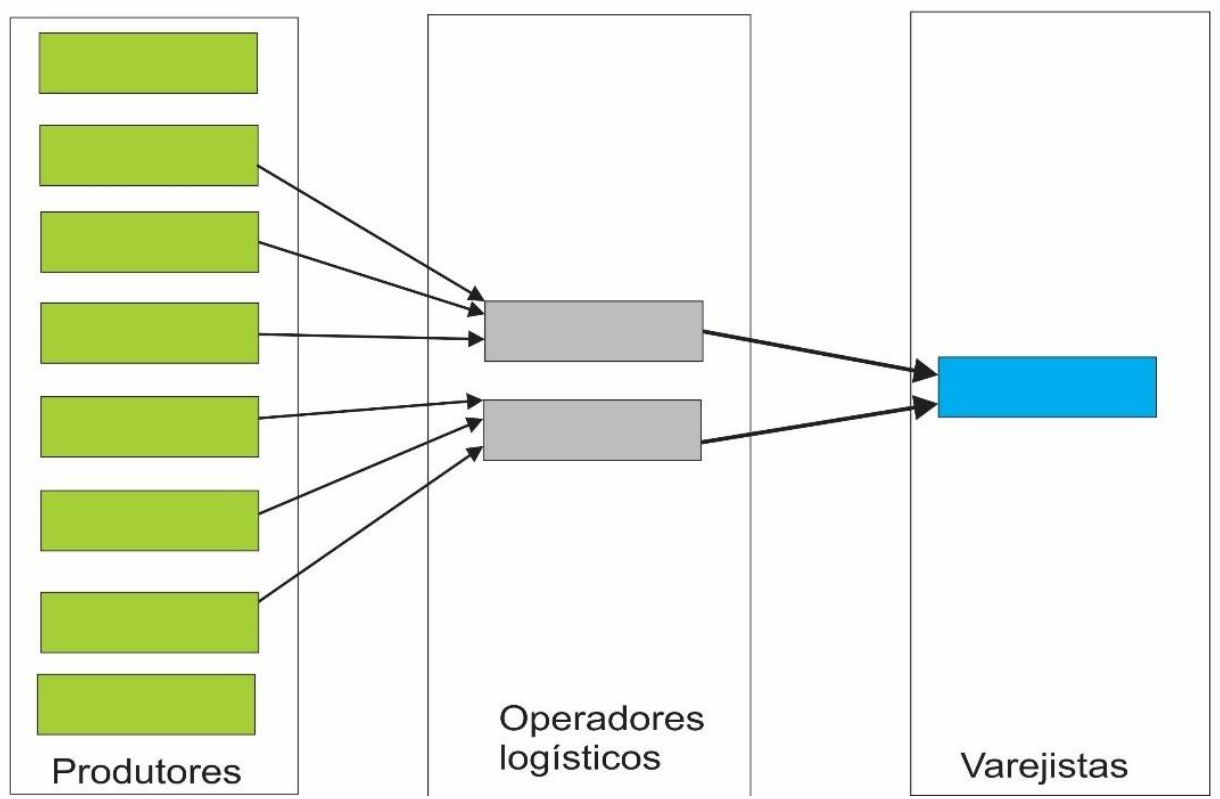

Figura 1. Redução de riscos logísticos.

Fonte: Marafon e Seabra. Trabalho de campo realizado em 2014.

As transformações em curso na comercialização agrícola no Estado do Rio de Janeiro são interações e reflexos de mudanças mais amplas na economia e na escala global. A construção de padrões técnicos e normativos para a circulação de fluxos de abastecimento modifica a dinâmica nas redes de comercialização de forma transescalar.

A acumulação flexível e os parâmetros neoliberais são determinantes para estabelecer novas relações derivadas de um jogo de escalas e dos processos historicamente enraizados no espaço fluminense. Assim, o novo não se estabelece na plenitude e, ao mesmo tempo, as permanências são entraves e potencialidades para a ação hegemônica de comercialização.

O sistema CEASA-RJ é uma permanência fundamental para a comercialização agrícola atual, apesar da centralidade exercida pelos supermercados. De fato, o sistema é hierarquizado, porém há trocas e articulações entre as posições hierárquicas que indicam a dinâmica disputa entre os agentes envolvidos na comercialização.

Nesse contexto, os supermercados buscam atravessar o controle do CEASA-RJ articulando, de forma direta, produção e comercialização. Contudo, a eficiência dessa relação logística passa pela contratação 
de operadores especializados na distribuição. Assim, a partir de práticas de terceirização, as redes varejistas contratam operadores logísticos (empresas de distribuição) mais competitivos e especializados na compra, separação e entrega de produtos agrícolas para as grandes redes localizadas na área metropolitana.

As empresas de distribuição são dotadas de um elevado padrão técnico, capaz de transformar a logística em diferencial competitivo e, simultaneamente, representam uma forma de agregar valor ao produto em virtude da maior competitividade desse canal de comercialização.

As ferramentas logísticas de eficiência e produtividade interagem com as relações sociais de produção estabelecidas nas áreas serrana e metropolitana, fomentando um arranjo espacial reticular transescalar extremamente dinâmico, com processos de marginalização e inclusão de produtores e operadores originados da imposição ou do mecanismo de resistência à lógica hegemônica.

A manutenção de mecanismos tradicionais de comercialização é uma necessidade dos agentes mais eficientes. Em geral, os produtores e as empresas menos capitalizadas formam redes marginais ao fluxo dos grandes operadores logísticos e dos grandes varejistas. Porém, as transformações conjunturais do mercado (re)criam condições de transformação do marginal em central sem romper com a hegemonia dos agentes centrais.

\section{CONSIDERAÇÕES FINAIS}

A presença de elementos modernos e tradicionais na comercialização agrícola na Região Serrana Fluminense representa, didaticamente, a expansão das possibilidades de reprodução ampliada do capital e a atual flexibilidade das formas de atuação e territorialização.

O modelo presente carrega temporalidades e espacialidades pretéritas em diferentes medidas e formas. Assim, a manutenção do sistema CEASA-RJ deriva da característica interventora do governo brasileiro naquele momento, e sua atuação hodierna revela a privatização da sua centralidade na 
comercialização de gêneros agrícolas. Nesse sentido, diante de uma proposta de reorientação das ações do Estado, há um claro atraso técnico das Ceasas, fomentando a entrada das grandes redes varejistas e operadores logísticos, (res)significando os parâmetros de eficiência e produtividade.

Assim, a logística torna-se um diferencial competitivo para as redes varejistas e, em tempo, amplia os canais e as possibilidades de escoamento da produção. Na Região Serrana, a diversidade de formas e tamanhos nas empresas de comercialização representa a coexistência de redes sobrepostas e articuladas. Da mesma forma, concebe interpretações para a função dos produtores familiares, pois há distintas atuações para o mesmo agricultor e até para o mesmo operador logístico.

Portanto, o entreposto comercial é uma permanência de outra temporalidade com a mesma função; entretanto,marginalizada pela lógica mercantil.Os produtores são inseridos (se inserem) e marginalizados (se excluem) das conexões de acordo com suas possibilidades e necessidades de reprodução social. O número de conexões não indica apenas a necessidade ou a possibilidade e sim a hegemonia de alguns agentes a partir da capacidade de gestão dos fluxos. A maior capacidade de gestão dos fluxos é dos varejistas e, em seguida, dos operadores logísticos, pela maior capacidade técnica e maior controle da demanda por produtos. Isso posto, esta análise revela a perspectiva transescalar das redes varejistas e a assimetria na sua atuação, em comparação com os produtores e operadores logísticos.

\section{REFERÊNCIAS}

CORREA, R. L. A Rede Urbana. 2 ed. Rio de Janeiro: Ática, 1985.

Interações Espaciais. In: CASTRO, I.; GOMES, P. C.; CORREA, R. L. (Org.). Explorações Geográficas. Rio de Janeiro: Bertrand Brasil, 1997. p. 279-318.

Estudos Sobre a Rede Urbana. Rio de Janeiro: Bertrand Brasil, 2006.

HAESBAERT, Rogério. 0 mito da desterritorialização: do “fim dos territórios” à multi-territorialidade. Rio de Janeiro: Bertrand Brasil, 2004.

MOREIRA, Ruy. Uma Análise Crítica do Modelo de Desenvolvimento do Estado do Rio de Janeiro. In: 0 Estado do Rio no Início do Século XXI: olhando para o futuro. Rio de Janeiro: Universidade Federal Fluminense, 2001. p.127-132. 
MARX, KARL. Valor, Trabalho e Mais-valia. In: NETTO, José Paulo. o leitor de Marx. Rio de Janeiro: Civilização Brasileira, 2012.

NOVAES, A. G. Logística e Gerenciamento da Cadeia de Distribuição. Rio de Janeiro: Campus. 2004.

SANTOS, Milton. Por uma outra globalização - Do pensamento único à consciência universal. Rio de Janeiro: Record, 2000 .

A natureza do Espaço: técnica e tempo, razão e emoção. São Paulo: Edusp. 2002.

Por uma geografia nova. São Paulo: Edusp, 2002b.

Da totalidade ao lugar. São Paulo: EDUSP, 2005.

Pensando o Espaço do Homem. São Paulo: EDUSP, 2007.

.Espaço e Método. Coleção Espaços. 5ª ed. São Paulo: Edusp, 2012 